\title{
Strategi Marketing Produk Tabungan Bank BJB Dalam Meningkatkan Customer Experience
}

\author{
Risma Indriani ${ }^{1}$, Maya Astria Lestari ${ }^{2}$, Ramayani Yusuf ${ }^{3}$ \\ ${ }^{1,2}$ Politeknik Piksi Ganesha Bandung \\ Jl.Gatot Subroto No.301, Maleer, Kec.Batununggal, Kota Bandung, Jawa Barat 40274, Indonesia \\ ${ }^{3}$ Universitas Pendidikan Indonesia \\ Jl. Dr. Setiabudi No.229, Isola, Kec. Sukasari, Kota Bandung, Jawa Barat 40154, Indoesia \\ E-mail: ${ }^{1}$ rindriani@piksi.ac.id, ${ }^{2}$ malestari@piksi.ac.id, ${ }^{3}$ ramayani.yusuf@piksi.ac.id
}

\begin{abstract}
\begin{tabular}{llll}
\hline Informasi Artikel & Diterima: 06-07-2021 & Direvisi: 02-08-2021 & Disetujui: 06-08-2021
\end{tabular}
Abstrak

Penelitian ini bertujuan untuk mengetahui bagaimana pengaruhnya Strategi Marketing produk Tabungan di dunia perbankan dalam meningkatkan Customer Experience. Penelitian ini, dilakukan di Bank BJB di cabang Asia Afrika Bandung. Survei dilakukan kepada nasabah yang mempunyai salah satu produk Tabungan Bank BJB. Dalam penelitian ini terdapat 97 responden yang diambil secara acak sederhana dari jumlah 2.889 nasabah yang tercatat. Metode pada penelitian merupakan kuantitatif korelasi. Teknik pengumpulan data yang diambil untuk penelitian ini melalui kuesioner kepada responden yang disebar dengan alat bantu google form. Penelitian ini menggunakan uji validitas dan uji reliabilitas, data uji asumsi klasik, dan juga model persamaan uji regresi linear sederhana. Alat analisis yang dipakai dalam proses riset ini, yaitu diselesaikan dengan dukungan memakai alat bantu komputer IBM SPSS 26. Berdasarkan pada hasil penelitian ini, menunjukan jika strategi marketing itu sangat berpengaruh signifikan positif dalam meningkatkan customer experience.
\end{abstract}

Kata Kunci: Strategi Marketing, Customer Experience, BJB

\begin{abstract}
This study aims to determine how the influence of the Marketing Strategy of Savings products in the banking world in improving Customer Experience. This research was conducted at Bank BJB in the Asia Afrika Bandung branch. The survey was conducted on customers who have one of the BJB Bank Savings products. In this study, 97 respondents were taken at simple random from a total of 2,889 registered customers. The method in this research is a quantitative correlation. Data collection techniques were taken for this research through questionnaires to respondents distributed using the google form tool. This study uses validity and reliability tests, classical assumption test data, and also a simple linear regression test equation model. The analytical tool used in this research process was completed with the support of using the IBM SPSS 26 computer tool. Based on the results of this study, it shows that the marketing strategy has a significant positive effect on improving customer experience.
\end{abstract}

Keywords: Marketing Strategy, Customer Experience, BJB

\section{Pendahuluan}

Pertumbuhan dunia perbankan yang semakin terus pesat dan diiringi pula dengan tumbuhnya minat masyarakat dalam memakai produk yang diajukan dengan teknologi canggih, hingga masyarakat dapat mempunyai banyak berbagai macam opsi dalam mengaplikasikan transaksi keuangan serta investasi dengan kilat juga tepat. Perbankan telah dianggap selaku sesuatu kebutuhan serta mitra dalam melaksanakan bisnis. Oleh sebab itu, bank sangat berperan penting dalam membantu nasabahnya untuk bertransaksi yang berhubungan dengan keuangan (Nurfazila \& Marlius, 2019).

Bank merupakan salah satu bagian terpenting dalam sistem perekonomian modern karena memiliki posisi strategis sebagai lembaga intermediasi, ialah mempertemukan dana dari masyarakat serta mengeluarkan kembali dengan berupa kredit pada masyarakat yang memerlukan, serta sebagai penunjang sistem pembayaran (Dahlia, 2017).

This work is licensed under a Creative Commons Attribution-ShareAlike 4.0 International License. 
Bank BJB ialah Bank BUMD milik pemerintah Jawa Barat serta Banten. Meskipun Bank BJB milik pemerintah, tetapi juga memberikan produk tabungan kepada masyarakat umum. Dengan banyaknya jenis produk tabungan perbankan, nasabah menjadi mudah dalam menentukan produk yang cocok dan sesuai dengan kebutuhannya.

Beberapa jenis produk tabungan Bank BJB diantaranya Tandamata, Tandamata Berjangka, Tandamata Bisnis, Tandamata Gold, Tandamata Purnabakti, Tandamata Dollar, Tandamata $M y$ First, Simpeda, dan TabunganKu (BankBJB, 2021).

Disaat ini, tiap bank dituntut supaya bisa menciptakan strategi marketing dalam membagikan dan menambah pelayanan pada nasabah supaya target perusahaan dapat tercapai. Strategi pemasaran dalam perbankan dilaksanakan secara terpadu sebagai usaha untuk kepuasan nasabah. Strategi marketing ialah ujung tombak untuk bank dalam mempromosikan serta juga memasarkan produk. Namun strategi pemasaran tidak hendak maksimal jika produk yang ditawarkan tidak mempunyai daya saing dibanding-kan dengan produk para pesaing (Fatimah \& Yansye Metekohy, 2013).

Dibutuhkan strategi marketing khusus agar suatu produk dapat mencapai customer experience yang optimal. Karena semakin baik customer experience yang dimiliki nasabah, maka semakin baik pula pengaruh terhadap citra perusahaan. Customer experience merupakan sebagai pengakuan kognitif atau persep simenstimulasi motivas ipelanggan. Pengakuan atau persepsi bisa juga menambah nilai produk serta jasa (Chen \& Lin, 2014) .

Menurut (Kasmir, 2014) menyatakan bahwa: "Dana pihak ketiga ialah dana yang dihimpun oleh bank, dan berasal dari masyarakat, seperti simpanan giro (demand deposit), simpanan tabungan (saving deposit), serta simpanan deposito (time deposit). Berikut merupakan info grafis statistik Perbankan Indonesia dalam setahun:

\section{Periode Februari 2020 - Februari 2021 (Rp Miliar)}

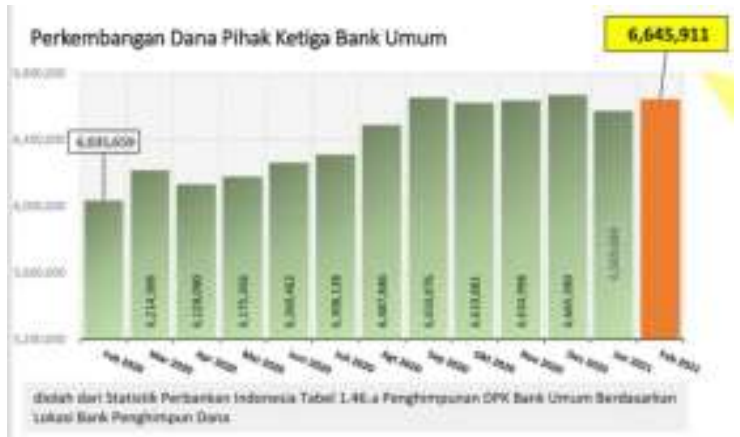

Sumber: (OtoritasJasaKeuangan, 2021) Gambar 1: Statistik Perbankan
Berdasarkan Gambar 1, data laporan info grafis statistik Perbankan Indonesia, jumlah dana pihak ketiga dari bulan ke bulan tidak stabil, karena mengalami peningkatan dan juga penurunan. Jumlah dana pihak ketiga terendah yaitu pada bulan Februari 2020 sebesar Rp 6.035.659. Sedangkan jumlah dana pihak ketiga terbesar yaitu pada bulan Desember 2020 sebesar Rp 6.665.390. Dari data tersebut, diperlukan strategi marketing untuk meningkatkan dana pihak ketiga (simpanan giro, simpanan tabungan, serta simpanan deposito).

Bank BJB dalam kreativitas dan inovasi bagi perusahaan merupakan sebuah kebutuhan dalam kelangsungan hidup suatu perusahaan. Dengan melakukan perubahan atau menciptakan ide-ide baru dalam produk maupun bidang teknologi, karena semakin banyak persaingan dalam dunia bisnis perusahaan.

Jumlah nasabah pengguna produk tabungan BJB Kcp Asia Afrika sifatnya fluktuatif dan bila dilihat dari tabel periode Februari 2020 Februari 2021 di bawah ini dapat dilihat bahwa pada bulan- bulan tertentu mengalami penurunan yang disebabkan nasabah tersebut menutup rekeningnya dengan berbagai alasan .

Tabel 1. Jumlah nasabah

\begin{tabular}{ccc}
\hline No & Bulan & Jumlah Nasabah \\
\hline 1. & Februari 2020 & 2.773 \\
2. & Maret 2020 & 2.666 \\
3. & April 2020 & 2.654 \\
4. & Mei 2020 & 2.688 \\
5. & Juni 2020 & 2.756 \\
6. & Juli 2020 & 2.731 \\
7. & Agustus 2020 & 2.738 \\
8. & September 2020 & 2.875 \\
9. & Oktober 2020 & 2.891 \\
10. & November 2020 & 2.904 \\
11. & Desember 2020 & 2.970 \\
12. & Januari 2021 & 2.864 \\
13. & Februari 2021 & 2.889 \\
\hline
\end{tabular}

Sumber diolah penulis, 2021

Dapat terlihat pada Tabel 1, jumlah nasabah pengguna produk tabungan BJB dari bulan ke bulan tidak stabil. Terjadi penurunan yang sesuai dengan gambar 1, penurunan paling tinggi di bulan Januari 2021. Untuk mempertahankan nasabah di BJB diperlukan strategi marketing agar tujuan perusahaan dapat tercapai dan juga tercipta customer experience.

Dalam dunia perbankan yang badan usahanya berorientasi profit, aktivitas pemasaran ialah sesuatu kebutuhan yang utama. Karena tanpa aktivitas pemasaran, jangan harapkan kebutuhan serta kemauan pelanggan hendak terpenuhi. Jadi, dalam dunia perbankan membutuhkan mengemas aktivitas pemasaran-nya agar secara terpadu terus dalam melaksanakan riset pasar (Tamara, 2016). Maka dari itu pentingnya strategi marketing bagi perusahaan, karena dapat berdampak sangat besar 
untuk kesuksesan perusahaan, sehingga semua target yang telah ditetapkan akan mudah tercapai.

Dari hasil pemaparan tersebut, penulis tertarik melakukan penelitian yang diberi judul: Strategi Marketing Produk Tabungan Bank BJB dalam Meningkatkan Customer Experience. (Studi kasus di Bank BJB Bandung).

\section{Metode Penelitian}

Metode penelitian merupakan tata cara yang utama digunakan peneliti untuk menggapai tujuan serta memastikan jawaban atas permasalahan yang diajukan (Arikunto, 2019). Sedangkan menurut (Darmadi, 2014), metode penelitian ialah sesuatu metode ilmiah agar memperoleh data informasi dengan tujuan tertentu.

Penelitian ini ialah penelitian kuantitatif, bersifat korelaso, dilihat dari cara mengumpulkan dan merekap data dengan menggunakan kuesioner. Pendekatan kuantitatif ialah riset yang berlandaskan filsafat positivisme dalam mempelajari populasi ataupun sampel tertentu, pengambilan sampel dengan random serta pengumpulan informasi memakai instrument, analisis informasi bersifat statistik (Sugiyono, 2018). Sedangkan metode penelitian korelasi ini berhubunngan dengan penilaian antara dua atau lebih fenomena.jenis penelitian ini biasanya melibatkkan ukuran statistik tingkat/derajat hubungan,yang disebut korelasi (Syamsudin \& Damiyanti: 2011). Adanya korelasi antara dua variabel atau lebih, tidak berarti adanya pengaruh atau hubungan sebab-akibat dari suatu variabel terhadap variabel lainnya.

Penelitian ini dilaksanakan untuk menganalisis bagaimana strategi marketing produk tabungan Bank BJB dalam meningkatkan customer experience. Variabel bebas (independent variable) atau variabel eksogen yang didapat di penelitian ini yakni Strategi marketing (X) dengan indikator (1) product (2) price (3) place (4) promotion dan (5) people. Sedangkan variabel terikat (dependent variable) atau variabel endogen pada penelitian ini adalah Customer experience (Y) dengan indikator (1) sense (2) feel (3) think (4) act dan (5) relate.

Penelitian ini dilakukan mulai Februari 2021 hingga April 2021 karena melihat kecenderungan penurunan jumlah nasabah yang terjadi di Bank BJB Asia Afrika. Objek penelitian pada studi ini adalah nasabah pada salah satu Bank BJB Kantor Cabang Pembantu di Bandung. Populasi sasaran penelitian ini merupakan nasabah yang menggunakan produk tabungan Bank BJB, dengan total sebanyak 2.889 nasabah pada salah satu Bank BJB Kantor Cabang Pembantu Asia Afrika Bandung. Dengan berdasarkan rumus slovin, dan margin of error yang ditetapkan $10 \%$ atau 0,1 maka hasil sampel yang diambil pada penelitian ini ialah sebanyak 97 sampel yang diambil secara random sampling.
Menurut (Sugiyono, 2015) variabel penelitian merupakan sesuatu atribut ataupun watak ataupun nilai dari objek ataupun aktivitas yang memiliki varian tertentu serta sudah dipastikan peneliti agar dipelajari serta setelah itu diambil pula intinya.

Tabel 2: Operasionalisasi Variabel

\begin{tabular}{|c|c|c|}
\hline Variabel & Definisi Operasional & Indikator \\
\hline $\begin{array}{l}\text { Strategi } \\
\text { Marketing }\end{array}$ & $\begin{array}{lr}\text { Strategi } & \text { pemasaran } \\
\text { ialah logika } & \text { pemasaran } \\
\text { dimana } & \text { industri } \\
\text { berharap } & \text { bisa } \\
\text { menghasilkan } & \text { nilai } \\
\text { untuk customer serta } \\
\text { bisa menggapai ikatan } \\
\text { yang profitabel dengan } \\
\text { pelanggan (Amstrong \& } \\
\text { Kotler, 2012). }\end{array}$ & $\begin{array}{l}\text { 1. Product } \\
\text { 2. Price } \\
\text { 3. Place } \\
\text { 4. Promotion } \\
\text { 5. People }\end{array}$ \\
\hline $\begin{array}{l}\text { Customer } \\
\text { Experienc } \\
e\end{array}$ & $\begin{array}{l}\text { Dalam menghasilkan } \\
\text { customer experience } \\
\text { yang luar biasa terdapat } \\
2 \text { perihal yang wajib } \\
\text { dicermati. Awalnya } \\
\text { buatlah preposisi janji } \\
\text { experience memiliki } \\
\text { daya minat, agar } \\
\text { customer tertarik } \\
\text { datang, serta yang ke- } \\
\text { dua merupakan } \\
\text { memperkenalkan } \\
\text { realitas customer } \\
\text { experience yang sama } \\
\text { dengan komitmen. } \\
\text { Apabila ke-duanya } \\
\text { sesuai, maka customer } \\
\text { experience hendak } \\
\text { timbul serta pula } \\
\text { menyebabkan kesetiaan } \\
\text { pelanggan dalam jangka } \\
\text { waktu yang panjang } \\
\text { (Hijjah \& Ardiansari, } \\
\text { 2015). }\end{array}$ & $\begin{array}{ll}\text { 1. } & \text { Sense } \\
\text { 2. } & \text { Feel } \\
\text { 3. } & \text { Think } \\
\text { 4. Act } \\
\text { 5. } \text { Relate }\end{array}$ \\
\hline
\end{tabular}

Sumber: diolah penulis, 2021

Dapat terlihat pada Tabel 2, bahwa ada keterkaitan antara strategi marketing dan customer experience. Karena jika suatu perusahaan mempunyai strategi marketing, maka menciptakan atau meningkatkan customer experience.

\section{Hasil dan Pembahasan}

Populasi yang dimanfaatkan dalam riset ini ialah nasabah BJB yang melakukan transaksi tabungan. Jumlah populasi adalah nasabah yang terdaftar di kcp sejumlah 2.889 orang. Berdasarkan rumus slovin diambil 97 responden, profil responden sebagai berikut:

Tabel 3: Tabel Profil Populasi

\begin{tabular}{lccc}
\hline Identitas & Indikator & Jumlah & Keterangan \\
\hline Jenis & Laki - Laki & 34 & - \\
kelamin & Perempuan & 63 & - \\
\hline
\end{tabular}




\begin{tabular}{llcc}
\hline Identitas & Indikator & Jumlah & Keterangan \\
\hline Umur & $<20$ tahun & 18 & \\
& $21 \quad-\quad 30$ & 74 & - \\
& tahun & 4 & - \\
& $31 \quad 40$ & 1 & - \\
& tahun & & - \\
& $>41$ tahun & & \\
Pekerjaan & Siswa / & 53 & \\
& Mahasiswa & 0 & - \\
& PNS & 27 & - \\
& Pegawai & 8 & - \\
& Swasta & 3 & - \\
& Wiraswasta & 6 & - \\
& Pegawai & & - \\
& BUMD & & \\
Lain-lain & & \\
\hline
\end{tabular}

Sumber: diolah penulis, 2021

Tabel 3 menunjukkan data profil populasi, data yang diambil merupakan identitas beserta jumlah per indikator. ini adalah:

Pernyataan yang diajukan dalam penelitian

Tabel 4: Tabel Daftar Pernyataan

\begin{tabular}{|c|c|c|}
\hline No & & Pernyataan \\
\hline 1. & & 1. Profil Responden \\
\hline \multicolumn{3}{|c|}{ Indikator (Variabel X) } \\
\hline 2. & Product & $\begin{array}{l}\text { 2. Tabungan Bank BJB } \\
\text { memberikan banyak manfaat } \\
\text { 3. Tabungan Bank BJB } \\
\text { memberikan banyak kemudahan }\end{array}$ \\
\hline 3. & Price & $\begin{array}{l}\text { 4. Setoran awal tabungan Bank BJB } \\
\text { terjangkau }\end{array}$ \\
\hline 4. & Place & $\begin{array}{l}\text { 5. Lokasi Bank BJB yang strategis } \\
\text { dan mudah ditemukan }\end{array}$ \\
\hline 5. & $\begin{array}{l}\text { Promotio } \\
n\end{array}$ & $\begin{array}{l}\text { 6. Program undian Bank BJB } \\
\text { menarik }\end{array}$ \\
\hline 6. & People & $\begin{array}{l}\text { 7. Bank BJB merespon dengan } \\
\text { cepat terhadap kebutuhan } \\
\text { maupun keluhan nasabah } \\
\text { 8. Pelayanan ramah dan sopan }\end{array}$ \\
\hline
\end{tabular}

\begin{tabular}{|c|c|c|}
\hline \multicolumn{3}{|c|}{ Indikator (Variabel Y) } \\
\hline 7. & Sense & $\begin{array}{l}\text { 9. Kartu ATM memberikan } \\
\text { banyak fasilitas } \\
\text { 10. Transaksi di Bank BJB mudah }\end{array}$ \\
\hline 8. & Feel & $\begin{array}{l}\text { 11. Proses transaksi di Bank BJB } \\
\text { memuaskan } \\
\text { 12. Kualitas pelayanan Bank BJB } \\
\text { baik }\end{array}$ \\
\hline 9. & Think & $\begin{array}{l}\text { 13. Biaya admisnistrasi bulanan } \\
\text { Bank BJB kecil }\end{array}$ \\
\hline 10. & Act & $\begin{array}{l}\text { 14. Produk yang ditawarkan Bank } \\
\text { BJB menarik } \\
\text { 15. Hadiah program undian Bank } \\
\text { BJB menarik }\end{array}$ \\
\hline 11. & Relate & $\begin{array}{l}\text { 16. Saya akan merekomendasikan } \\
\text { produk Tabungan Bank BJB }\end{array}$ \\
\hline
\end{tabular}

Berdasarkan pada Tabel 4, merupakan kuesioner yang dibuat untuk memenuhi keperluan data, dengan bantuan Google Form yang ditujukan untuk nasabah pengguna Produk Tabungan Bank BJB.

Dari hasil yang di dapat setelah penyebaran kuesioner kepada 97 nasabah Bank BJB dan menggunakan SPSS 26 diperoleh hasil seperti dijelaskan dibawah ini.

\section{Analisis Data Kuantitatif}

\section{1). Uji Validitas}

Uji validitas merupakan uji yang dimanfaatkan untuk menampilkan bagaimana instrumen yang dimanfaatkan dalam sesuatu tindakan memperkirakan apa yang di-ukur. Sebuah survey dianggap sah jika persoalan dalam kuesioner dapat mengungkap suatu yang hendak diukur oleh survey tersebut (Yusuf et al., 2018). Tabel 5: Hasil Uji Validitas

\begin{tabular}{ccc}
\hline Indikator & Nilai & Keterangan \\
\hline x1 & 0,771 & Valid \\
x2 & 0,773 & Valid \\
x3 & 0,704 & Valid \\
x4 & 0,674 & Valid \\
x5 & 0,062 & Valid \\
x6 & 0,786 & Valid \\
x7 & 0,657 & Valid \\
y1 & 0,509 & Valid \\
y2 & 0,706 & Valid \\
y3 & 0,688 & Valid \\
y4 & 0,743 & Valid \\
y5 & 0,769 & Valid \\
y6 & 0,752 & Valid \\
y7 & 0,141 & Tidak Valid \\
\hline
\end{tabular}

Sumber: diolah penulis, 2021

Berdasarkan Tabel 5, hasil uji validitas menampilkan ada 1 item yang tidak valid sehingga indicator tersebut tidak dapat digunakan untuk melanjutkan penelitian. Sedangkan data yang lainnya adalah sah atau valid dan dapat digunakan sebagai instrumen penelitian dengan alasan bahwa nilai dari semua item lebih dari 0,5. Pertanyaan yang terkandung dalam angket penelitian dapat digunakan untuk pemeriksaan tambahan.

\section{2). Uji Reliabilitas}

Uji reliabilitas sesungguhnya fitur untuk menaksir kuesioner yang termasuk indikator dari variabel atau juga konstruk. Dalam riset ini, untuk menguji reliabilitas tiap-tiap instrumen, penulis memakai uji statistik Cronbach Alpha ( $\alpha$ ). Perhitungan reliabilitas menggunakan Cronbach Alpha $(\alpha)$ diselesaikan dengan dukungan komputer IBM SPSS 26. Instrumen dikatakan reliable apabila Cronbach Alpha dinilai > 0,70 (Ghozali, 2016).

\begin{tabular}{|c|c|}
\hline \multicolumn{2}{|c|}{$\begin{array}{c}\text { Tabel 6: Hasil Cronbach's Alpha } \\
\text { Reliability Statistics }\end{array}$} \\
\hline Cronbach's Alpa & $\mathrm{N}$ of items \\
\hline .965 & 14 \\
\hline
\end{tabular}

Sumber: diolah penulis, 2021

Bedasarkan pada Tabel 6, hasil dari reliabilitas penelitian ini menunjukkan nilai $0,965>$ 
0,70, sehingga tanggapan yang tepat dari responden adalah reliable bahwa setiap pertanyaan dalam kuesioner dapat dimanfaatkan dan dapat dikirim sebagai instrumen penelitian.

\section{Data Asumsi Klasik \\ 1). Uji Multikolinieritas}

Uji multikolinieritas dimanfaatkan dalam menguji apa model regresi terdapat hubungan antara korespondensi variabel bebas. Model regresi yang benar dan baik semestinya tidak memiliki hubungan antara variabel independent. Pengujian terdapat atau tidaknya indikasi multikolinearitas dilakukan dengan mempertimbangkan nilai kisi-kisi hubungan yang dihasilkan selama penanganan informasi seperti nilai VIF (Variance Inflation Factor) serta resistansinya.(Yusuf et al., 2018)

\begin{tabular}{|c|c|c|c|}
\hline \multirow[b]{2}{*}{ Model } & & \multicolumn{2}{|c|}{$\begin{array}{c}\text { Collinearity } \\
\text { Statistics }\end{array}$} \\
\hline & & Tolerance & VIF \\
\hline \multirow[t]{8}{*}{1} & (Constant) & & \\
\hline & $\mathrm{X} 1$ & .229 & 4.361 \\
\hline & $\mathrm{X} 2$ & .309 & 3.232 \\
\hline & X3 & .339 & 2.949 \\
\hline & $\mathrm{X} 4$ & .467 & 2.141 \\
\hline & $\mathrm{X} 5$ & .337 & 2.963 \\
\hline & X6 & .284 & 3.516 \\
\hline & $\mathrm{X} 7$ & .388 & 2.575 \\
\hline
\end{tabular}

Sumber: diolah penulis, 2021

Dapat terlihat pada Tabel 7, hasil dari nilai $\mathrm{x}$ menunjukkan $<10$ sehingga tidak terjadi multikolinearitas antar variabel.

\section{2). Uji Heteroskedastisitas}

Uji Heteroskedastisitas ber-tujuan dalam memverifikasi apa pada model regresi terdapat varians perbedaan dari residuary satu persepsi dengan persepsi lainnya. Pada pengujian ini Uji Heteroskedastisitas dengan Grafik Plot (Ghozali, 2016).

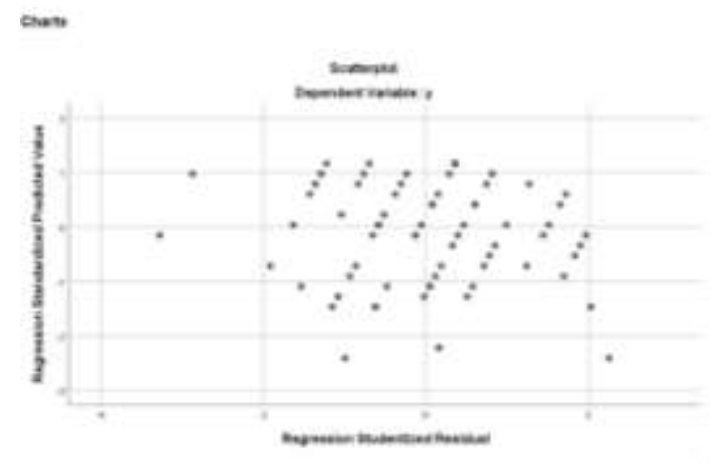

Gambar 2: Grafik Scatter

Berdasarkan Gambar 2, hasil dari peredaran plot tersebut tidak membentuk gelombang besar yang lebar namun tidak berbentuk pola tertentu,

Pandangan ini menunjukkan jika ia terbebas dari heteroskedastisitas. hasil:

Dengan menggunakan Uji Glejser diperoleh

Tabel 8: Hasil Uji Glejser

\begin{tabular}{|c|c|c|c|c|c|}
\hline & & Coeffic & & & \\
\hline \multirow[b]{2}{*}{ Model } & \multicolumn{2}{|c|}{$\begin{array}{l}\text { Unstandardized } \\
\text { Coefficients }\end{array}$} & $\begin{array}{l}\text { Standardized } \\
\text { Coefficients }\end{array}$ & \multirow[b]{2}{*}{$\mathrm{t}$} & \multirow[b]{2}{*}{ Sig. } \\
\hline & B & Std. Error & Beta & & \\
\hline 1 (Constant) & 12.898 & 3.003 & & $\begin{array}{r}4 . \\
29 \\
4\end{array}$ & .007 \\
\hline $\mathrm{x} 1$ & 1.219 & .086 & .816 & $\begin{array}{r}14 \\
.1 \\
36\end{array}$ & .006 \\
\hline
\end{tabular}

a. Dependent Variable: y

Dapat terlihat pada Tabel 8 , karena nilai signifikasi > 0,05, maka dapat dapat disimpulkan bahwa tidak terjadi gejala heterokedasitas pada model ini.

\section{3). Uji Normalitas}

Uji normalitas dimanfaatkan dalam mengukur apa yang dalam model regresi, suatu variable independent serta variable dependent atau pun ke-duanya memiliki penyebaran yang biasa ataupun tidak biasa. Apabila sesuatu variabel tidak berdistribusi dengan biasa, hingga hasil uji statistik hendak alami penyusutan. Uji normalitas data bisa diselesaikan dengan memakai uji One Sample Kolmogorov Smirnov, dengan syarat jika nilai signifikasi di atas 5\% ataupun 0,05 hingga data tersebut mempunyai sirkulasi yang biasa. Sebaliknya bila hasil uji One Sample Kolmogorov Smirnov memberikan hasil nilai $<5 \%$ ataupun 0,05 hingga data tersebut tidak mempunyai sirkulasi biasa ataupun wajar (Ghozali, 2016).

Tabel 9: Hasil Uji Normalitas One-Sample Kolmogorov-Smirnov Test

\begin{tabular}{|c|c|c|}
\hline & & $\begin{array}{c}\text { Unstandardized } \\
\text { Residual } \\
\end{array}$ \\
\hline $\mathrm{N}$ & & 102 \\
\hline \multirow{3}{*}{ Normal Parameters ${ }^{\mathrm{a}, \mathrm{b}}$} & Mean & .0000000 \\
\hline & Std. & 4.57566434 \\
\hline & Deviation & \\
\hline \multirow[t]{3}{*}{ Most Extreme Differences } & Absolute & .119 \\
\hline & Positive & .119 \\
\hline & Negative & -.075 \\
\hline \multicolumn{2}{|l|}{ Test Statistic } & .119 \\
\hline \multicolumn{2}{|c|}{ Asymp. Sig. (2-tailed) } & $.006^{\mathrm{c}}$ \\
\hline \multicolumn{3}{|c|}{$\begin{array}{l}\text { a. Test distribution is Normal. } \\
\text { b. Calculated from data. } \\
\text { c. Lilliefors Significance Correction. }\end{array}$} \\
\hline \multicolumn{3}{|c|}{ Sumber: diolah penulis, 2021} \\
\hline
\end{tabular}

Berdasarkan Tabel 9, hasil nilai dari uji Kolmogorov Smirnov menunjukan lebih > 0,05 sehingga variabel bebas maupun terikat terdistribusi secara normal.

\section{4). Uji Koefisien Regresi Linier Sederhana}

Analisis regresi merupakan untuk menentukan pilihan apa terdapat kenaikan serta penurunan variable dependent bisa dicoba melalui peningkatkan variable independent ataupun tidak. Regresi sederhana tergantung pada ikatan fungsional atau kausal antara satu variable independent dengan variable dependent. Analisis regresi digunakan untuk memperkirakan seberapa jauh penyesuaian nilai variable dependent, apakah 
variable independent dikendalikan atau dimanipulasi atau diganti ataupun dinaik-dikurangi (Sugiyono, 2017).

Tabel 10: Hasil Uji Koefisien Regresi Linier Sederhana

\begin{tabular}{lccccc}
\hline & $\begin{array}{c}\text { Unstan } \\
\text { dardize } \\
\text { Model }\end{array}$ & $\begin{array}{c}\text { Coeffi } \\
\text { cients } \\
\text { Std. }\end{array}$ & $\begin{array}{c}\text { Standa } \\
\text { rdized } \\
\text { Coeffic } \\
\text { Error }\end{array}$ & $\begin{array}{c}\text { T } \\
\text { ients } \\
\text { Beta }\end{array}$ & Si \\
\hline $\begin{array}{l}\text { (Const } \\
\text { and })\end{array}$ & 3.960 & 1.080 & & 3.6 & .0 \\
& & & & 67 & 0 \\
$\mathrm{X}$ & .867 & .037 & .924 & 23. & .0 \\
& & & & 514 & 0 \\
& & & & & 0
\end{tabular}

Sumber: diolah penulis, 2021

$\mathrm{Y}=3.960+0,924 \mathrm{x}$

Berdasarkan Tabel 10, persamaan linear sederhana ini menjelaskan konstanta sebesar 3.960, jadi apabila strategi marketing (x) nilai-nya yaitu 0 , maka customer experience (Y) nilai-nya ialah 3.960. koefisien regresi variabel strategi marketing (x) sebesar 0,924, maksudnya apabila variable independen lain nilai-nya tetap serta strategi marketing alami kenaikan $1 \%$ maka nilai customer experience (Y) hendak menghadapi peningkatan sebesar 0,924 .

Tabel 11: $\mathrm{R}^{2}$

Model Summary ${ }^{b}$

\begin{tabular}{llrrr}
\hline $\begin{array}{l}\text { Mod } \\
\text { el }\end{array}$ & $\mathrm{R}$ & $\begin{array}{c}\mathrm{R} \\
\text { Square }\end{array}$ & $\begin{array}{c}\text { Adjusted R } \\
\text { Square }\end{array}$ & $\begin{array}{c}\text { Std. Error } \\
\text { of the } \\
\text { Estimate }\end{array}$ \\
\hline 1 & $.816^{\mathrm{a}}$ & .666 & .663 & 4.598
\end{tabular}

a. Predictors: (Constant), x1

b. Dependent Variable: $y$

Berdasarkan Tabel 11, hasil dari $\mathrm{R}$ square menunjukkan angka 0,666, artinya sebesar $66,6 \%$ strategi marketing meningkatkan customer experience, sedangkan 33,4\% dipengaruhi faktor lainnya yang tidak diteliti dalam penelitian ini.

Koefisien bernilai positif maksudnya terjalin ikatan positif antara strategi marketing dengan customer experience, hingga terus menjadi naik customer experience.

\section{Kesimpulan}

Dari hasil penelitian yang telah dilaksanakan, Bank BJB banyak memiliki banyak produk tabungan yang memudahkan nasabahnya, untuk menyesuaikan produk tabungan apa yang dibutuhkan nasabah. Dari dilakukannya strategi marketing produk sangat berpengaruh dalam meningkatkan customer experience. Dan untuk melihat persaingan yang sangat ketat diperlukan strategi menciptakan customer experience yang dapat memberikan kepuasan.

\section{Referensi}

Amstrong, G., \& Kotler, P. (2012). Dasar-dasar Pemasaran. Jakarta: Prenhalindo.

Arikunto, S. (2019). Prosedur Penelitian. Jakarta : Rineka Cipta.

BankBJB. (2021). Tabungan Bank BJB. Www.Bankbjb.Co.Id. https://www.bankbjb.co.id/tentang/ina/profil/pro duklayanan

Chen, S.-C., \& Lin, C.-P. (2014). The impact of customer and perceived value on sustainable social relationship in blogs: An empirical study.

Dahlia, I. (2017). Analisis Strategi Pemasaran Bank Bjb Kcp Babelan Cabang Cikarang Tahun 2016 Skripsi Oleh : Intan Dahlia Program Studi Manajemen Sekolah Tinggi Ilmu Ekonomi Pelita Bangsa. 1-104.

Darmadi, H. (2014). Metode Penelitian Pendidikan Sosial. Bandung : Alfabeta.

Fatimah, \& Yansye Metekohy, E. (2013). Strategi Pemasaran Produk Pembiayaan Murabahah pada Bank X Syariah Cabang Tangerang Selatan. 12(1), 75-82.

Ghozali, I. (2016). Aplikasi Analisis Multivariate Dengan Program IBM SPSS 23 (8th ed.). Universitas Diponegoro Semarang.

Hijjah, R., \& Ardiansari, A. (2015). Pengaruh Customer Experiance dan Customer Value Terhadap Customer Loyalty melalui Customer Satisfaction. Manajemen Analysis Journal.

Kasmir. (2014). Dasar-dasar Perbankan. Jakarta : Raja Grafindo Persada.

Nurfazila, \& Marlius, D. (2019). Aktivitas Pemasaran Tabungan Pada Pt.Bank Pembangunan Daerah Sumatera Barat Cabang Pembantu Tarusan. 68-70.

OtoritasJasaKeuangan. (2021). Statistik Perbankan Indonesia. Www.Ojk.Co.Id. https://www.ojk.go.id/id/kanal/perbankan/datadan-statistik/statistik-perbankanindonesia/Pages/Statistik-Perbankan-Indonesia--Februari-2021.aspx

Sugiyono. (2015). Metode Penelitian Kombinasi (Mix Methods). Bandung: Alfabeta.

Sugiyono. (2017). Metode Penelitian Kuantitatif, Kualitatif, dan R\&D. Bandung: Alfabeta.

Sugiyono. (2018). Metode Penelitian Kuantitatif, Kualitatif, dan $R \& D$. Bandung : Alfabeta.

Tamara, A. (2016). Implementasi Analisis Swot Dalam Strategi Pemasaran Produk Mandiri Tabungan Bisnis. Jurnal Riset Bisnis Dan Manajemen, 4(3), 395-406.

Yusuf, R., Hernawati, E., \& Solihat, A. (2018). Layanan SMS Banking dan Internet Banking Bank Syairah untuk meningkatkan Customer Experience. BENEFIT Jurnal Manajemen Dan Bisnis. 